\title{
Music Preferences, Music Engagement and Healing
}

\author{
Durgesh K. Upadhyay
}

\begin{abstract}
Present paper aimed to explore and understand the nature of engagement of college students with music, their music preferences and their experiences of 'healing through music'. A questionnaire, consisted of nine questions including trio of closed, open-ended and open-ended questions with partial pre-coding, was administered on two compare groups, music listeners $\left(n_{1}=44\right)$ and music learners $\left(n_{2}=45\right)$ of college students $(\mathrm{N}=89)$ from two universities. These two comparable groups were found having effect in terms of differences in students' nature of music engagement, their music preferences, and their subjective healing experiences. Findings of this study provide insight about the musical taste, the relationships between affective state and music listening, and the manifold and multilevel healing experiences with music of both music listeners and learners. These findings may be useful in designing the music intervention plans to alleviate the human sufferings and in turn to promote psychological health and well-being in so called normal population.
\end{abstract}

Index Terms-Music, music preference, musical engagement, healing.

\section{INTRODUCTION}

What are the connections between us and music? The answers include: the pleasure gained from listening; the warmth and friendship from being part of a group making music; the stimulus and satisfaction from regular practice and rehearsal; the intellectual delight from exploring the intricacies of musical forms and structures; the physical energy released within us by both playing and listening to music, inspiring us often to move and dance. [1]

These lines provide the context for this study. Music, which is ubiquitous, is present everywhere in our surroundings. It is in the focus of many activities, one of the most frequent leisure activities especially among adolescents. There are at least three ways how people can relate to music namely, as a composer, as a performer (by means of their voice or an instrument), and as a listener. The work in hand concentrates on music listening because it is the most ubiquitous activity which concerns every single individual whether he is a composer, a performer or simply a listener. Music psychology is related to music listening in several respects which will accompany this whole work: Why do we listen to music at all? What kind of music do we listen to and why? How strong is our relation to specific music and why? What are our healing experiences because of listening to some music? What is the role of the context in which the music is heard?

Manuscript received March 9, 2013; revised May 22, 2013.

Durgesh K. Upadhyay is with the Amity University Uttar Pradesh, India (e-mail: dkudurgesh@gmail.com).
North, Hargreaves and Hargreaves [2] argues that the value one places on the music in everyday life depends on the uses they make of it and the degree of engagement with it, which is dependent on the context in which the music is heard. 'Which music do we like?' has become one of the most often used questions in psychological research, for two reasons: First, since every person is in contact with music everyday and most people see music as one of the most important things in their daily life, the study of music listening provides an authentic and fruitful avenue to their experiences and behavior in a variety of situations and contexts. Second, because music has been recognized as a tool for expressing and inducing moods and emotions and also as a means to convey information in social environments, music is by now often used as an essential implement in personality, emotion, and social psychology research. Thus, research on music preference is going on to provide us with deep insights into many psychological questions.

\section{MUSIC PREFERENCE}

Findings about music preference-why we prefer one piece of music over another - are still very rare. And this may be one reason why to date there is still no conclusive theory on music preference. Such a theory is necessary to integrate the findings on music preference accumulated through the last decades, to organize (further) research in this area, and to gain a deeper understanding of why we listen to music at all which may, in turn, help to understand the role of music in human evolution. Not least, "a workable theory would assist teachers who need to know how preferences develop, and would help music therapists profit from new insights into the workings of a basic tool of therapy" [3].

Music preference has two dimensions: type and strength. The type of preference refers to the question which musical style a person likes best. The strength of preference refers to the degree to which one likes a musical piece/style. Music psychology has mainly concentrated on the type of music preference and asked for the reasons why different people prefer different kinds of music. The strength of music preference has widely been ignored, however. This is peculiar because the strength of music preference represents how strongly one is involved in music and thus is linked with the question why one actually listens to music.

Music preference is usually measured via questionnaires by means of Likert-type rating scales. It can be measured as either verbal or sounding preference [4]. Verbal preference refers to a research setting in which respondents are asked to think of a certain musical piece or style and rate how much they like it. In contrast, sounding preference refers to a 
research setting in which respondents are to listen to concrete musical pieces and then rate how much they enjoyed it. Whether both kinds of measurement yield different results has barely been investigated so far; but one could argue that sounding preferences are closer to real music listening [4]. However, in the vast majority of studies preference was measured verbally.

The variety of factors that have shown to have an influence on music preference can be divided into four groups of factors: the music, the listener, the context, and the use of music [5]. Moreover, Wapnick [6] and LeBlanc [3] believe that the listener's sex may influence musical preference, although Abeles's [7] literature review suggests otherwise, and LeBlanc, Sims, Malin, and Sherrill [8] found no significant differences. Several attitudinal research studies support the Wapnick and LeBlanc position, however. In each of these studies, females expressed significantly more positive attitudes than males toward music [9]. A study by LeBlac, Sims, Malin, and Sherrill [8] suggests that females, especially those of college age, pay much more attention to lyrics than do males.

Music attitudes and preferences have also been found to be related to prior instruction and experiences [10], including high school music experiences [11]. However, there appears to be no significant difference between music majors' and non-music majors' attitudes toward popular music [12].

In studies that focus on musical stimuli, researchers have examined relationships between various aspects of music and attitudes or preferences. LeBlanc [13] found that some variance in style preference of children was attributable to musical style (23\%), style and tempo (26\%), and style, tempo, and performance medium (28\%). In another study, young subjects identified melody, mood, rhythm, and lyrics as the most important musical components [14].

Though this study uses the term music preference, Abeles and Chung [15] make a distinction between a musical 'taste' and a musical 'preference.' They consider musical taste to be "a relatively stable, long-term valuing," with musical preference being defined as a more short term, spontaneous reaction to music. Russell [16] defines a taste as "a stable long-term preference." By this distinction, musical preference testing is usually conducted by playing subjects musical excerpts and having them respond. Conversely, musical taste is typically measured by questionnaires that usually require the subject to rank their opinions of musical genres.

\section{EFFECTS OF MUSIC LISTENING}

North et al. [2] conducted a study on music, refining investigation to the following areas: who individuals listen to music with; what they listen to; their emotional responses to this music; when they listen to music; where music is listened to, and why they listen to music.

One of the main approaches used to investigate media, and therefore music preference is the uses and gratification model [17]. This model assumes that individuals have a specific set of psychological and social needs (in areas such as personal identity, relationships and need for diversion) as well as a specific set of expectations as to how the mass media may gratify these needs, and that these contribute to an individual's media preferences [18]. Using this approach two areas of music preference have been examined: the use of music as a way to control mood [19], and as a way of signaling social identity [20]. It is believed that music is a key to an individual's identity as it offers a sense of both one's self and others. These experiences enable individuals to place themselves in imaginative cultural narratives [21].

Moreover, significant research is present detailing the use of music as a coping mechanism. It is believed that music regulates emotions by allowing a temporary escape from thoughts and feelings, or validates thoughts and feelings, which enables individuals to release pent up emotions, such as anxiety and anger [22]. Research by North, Hargreaves, et al. [2] found that listeners selected specific genres of music to elicit different effects within themselves and will likely continue to be used as, a diversion from stress and a coping mechanism for many people. Moreover, Upadhyay (in press) found that not only the music listening but also the music practice (Riazz) that was considered by most of the musicians as 'coping mechanism' was in itself able to heal their sufferings.

North et al. [2] conducted a study to establish whether music could be used to manipulate one's mood. Participants listened to music that was deemed positive and uplifting as well as music considered 'annoying' to determine if the music affected their emotional state. It was found that positive and uplifting music produced a positive and uplifting emotional state, whereas annoying music produced an agitated and annoyed emotional state within the participants. Wells [23] also found that both females and males use music to change their mood, established to be particularly true when feeling depressed, as it was concluded individuals used music at this time to uplift their spirits. Music, it has been found, helped individuals calm down or relax [23]. Laukka [24] found that music is a recurrent source of positive emotions and listeners tend to listen to a range of music that relates to their emotional functions.

Steele and Brown [25] report their participants commenting that they used music to enhance their mood ("When I need to get pumped up, like before a party, I listen to wild, loud music" p 565) or to cope with a feeling ("she liked to turn on her stereo and 'just wallow' in it ... find songs that are like the same as whatever kind of mood I'm in ... when I am sad I listen to sad music" p 566). Interestingly, Wheeler [9] found that the mood after listening to music was influenced by the mood before listening to the music. Thus, if the music heard is not a music preference, the individual will feel worse than beforehand. Conversely, if a person feeling badly listens to music they like, that person will feel better.

Against this backdrop, this study aimed to explore and understand the nature of music preferences and the experiences of 'healing through music' of college students (18-24 years) with music. In the Indian context, healing is seen as the process of alleviation of human suffering (dukhha) and attaining peace and well-being. The domain of healing subsumes within its fold treatment, cure, coping, recovery, sound health, therapy, well-being, and all that goes with them [26]. Music is one of the multiple systems, 
modalities or pathways to healing. Music operates in a socio-cultural field, and implicates certain cultural beliefs and practices, without which it is not possible to discuss what healing means.

\section{METHOD}

The sample $(N=89)$, made up of a convenience sample of college students attending Amity University and Banaras Hindu University, India, comprises two compare groups; music listeners $\left(n_{1}=44\right.$; Male $=16$, Female $\left.=28\right)$ and music learners $\left(n_{2}=45\right.$; Male $=24$, Female $\left.=21\right)$, aged between 17-26 and 17-28 respectively.

A sample of 45 music students (24 male and 21 female) and a sample of 44 non-music students (16 male and 28 female) were recruited from faculty of performing arts, Banaras Hindu University, Varanasi and Amity School of Languages, Amity University, Lucknow respectively. These numbers of samples, new, are final as it excluded those who didn't respond every question.

A self-report questionnaire consisted of nine questions including trio of closed, open-ended and open-ended questions with partial pre-coding was administered. Seven questions have been analyzed and reported.

\section{RESULTS}

\section{A. Musical Engagement}

Nearly one third of the music learners (73.33\%) enjoy listening to some music while engaged in some other work whereas more than half of the music listeners $(63.63 \%)$ don't enjoy. They have their own reasons. The most frequent response $(91.25 \%)$ was that they were not able to concentrate. Moreover, respondents' responses about why do they enjoy listening to some music while engaged in some other work and what are those works have been tabulated beginning with an example of the most frequently mentioned reasons.

\section{1) Why do they enjoy?}

Music listeners' reasons: 'To ease the pressure;' 'Makes me not getting bored;' 'To make concentration'; 'Soothes my mind and doesn't let me lazy.'

Music learners' reasons: 'To enjoy;' 'To keep myself interested;' 'Tasks seem easier;' 'To get concentration;'

'Helps in sleeping;' 'For satisfaction;' 'To be tension free and calm;' 'Refreshing mood;' 'Helps to create.'

\section{2) When do they enjoy listening to some music?}

Music listeners' responses were while driving, writing, cleaning the room, cooking, when the work is boring and doesn't need much mental work or attention, and solving mathematical problems

Music learners' responses were while reading nonmusical books, cooking, walking/wandering, anything I am doing, while making notes, and dancing

\section{B. Music Preferences}

Nearly half of the music listeners $(51.11 \%)$ preferred soft and slow music and a total of $42.22 \%$ music learners preferred soft music. On the other hand music listeners didn't show a clear cut preference. Music listeners (30\%) are more oriented to loud and fast music and the same total $(30 \%)$ preferred all types of music depending upon the several factors.

\section{1) Why do you have this preference?}

Music listeners' reasons for preferring soft music are as follows: Soothing effect on mind and body; depends on mood and situation; when I am in deep thought, it induces sleep; and when I feel upset or dull

Music listeners' reasons for preferring soft and slow music are as follows: When sad and alone; it's my private time when I do lie down and think about good old memories; and $I$ am able to relate and recognize such kind of music more easily

Music listeners' reasons for preferring loud and fast music are as follows: Lightens up the mood; pumps up my adrenalin level; it reduces all my stress; it makes my mood fresh, turns me on, and motivates to keep the problem aside and work harder

Music learners' reasons for preferring soft music are as follows: Never disturbs concentration; relaxes; clear to listen; to keep the mind and brain in harmony; it's my nature; stability and concentration; means to attain the divinity; good for sound sleep; and you can still have your own thoughts.

Music learners' reasons for preferring soft and slow music are as follows: I can feel it; washes away all the negativities from my thinking; changes mood; and gives pleasure and satisfaction

Music learners' preferred loud and fast music only when they drive.

\section{Music Listeners}

- Peace of mind

- Sets mood and decrease stress

- Makes us feel good and lively

- Short term affect

- 'You stop thinking about outside life and sometimes there is a song whose lyrics are so relative to what's happening in our life that it is a little calming and we get relaxed...'

- Music doesn't have the full capability to heal but it helps in aiding and helping to heal and soothes a person's brain and nerves.

- Music is the best remedy to cure our relationships

- It takes away anxiety. 1 song $=1000$ words

- Stimulates

- Music is a way to control your emotions. At an extreme its lyrics gives the different way to react to certain situation and the solutions are sometimes hidden in it.

- Music is beautiful. It's a remedy for a wounded heart, it can break down a person as well as boost up and make them happy. Music is spiritual and soothes the heart and mind

- Heals the mind from loneliness to freshness

- It helps overcome emotions

- Music makes one's inner suppressed feeling come out

- The divine voice makes the cells to vibrate. The rhythm and beats and tunes uplifts my mood 


\section{Affects of Music}

Nearly all music learners $(95.45 \%)$ reported the positive effects of music whereas nearly one third of music listeners $(27.90 \%)$ reported that music has both positive and negative effects.

\section{Context of Listening}

More than half of both the groups $(68.29 \%$ and $64.29 \%$ respectively) agreed that the particular place or physical setting makes the music more or less effective.

\section{E. Healing through Music}

Music learners get touched the most with human voice $(44.19 \%)$ and with stringed instruments like Sitar, Sarangi and Flute whereas in the case of music listeners, rhythmic pattern touches the most $(47.62 \%)$ and stringed instruments like Guitar and Violin.

Meaning of healing - Respondents' responses for 'healing through music' have been tabulated. This theme explores respondents' experiential implicit meaning of the term 'healing.'

\begin{tabular}{l} 
Music Learners \\
- Alters the mood \\
- It has changed my character and ways of \\
- Reduces pain \\
- Helps to meditate \\
it changes lifestyle, thoughts, and whole things \\
- Stress reduction (I was suffered from headache \\
badly so I couldn't study science. After that I \\
started learning music) \\
- Amazing change in my thinking, thoughts and \\
behaviour. The more I am going deeper into the \\
music I am enjoying the eternal peace. It has \\
transformed my life. \\
Listening to music helps me to forget all my \\
sufferings for some time. It induces positive \\
energy \\
The best way for relaxation, refreshment, \\
expression. Helps in taking correct decision \\
\hline
\end{tabular}

\section{CONCLUSION}

This study was an attempt to explore and understand the nature of engagement of college students with music, their music preferences and their experiences of healing through music. It has compared two groups: music listeners and music learners.

Results show that music is mainly an accompaniment to other activities rather than a focused activity for music listeners, which supports previous studies on everyday music listening (e.g. [27]). Results also show that college students are more likely to have choice over music whilst engaged in personal maintenance and active leisure pursuits, when at home or when travelling, and when they are alone [27].

Both music listeners and learners are more likely to have choice over hearing music when at home and driving and less likely to have choice in social settings such as the gym or shops; and more likely to have choice when they were alone rather than with other people [2].

While people reported higher liking for music listening alone [2], research has not yet examined in detail the role of others in determining people's musical choices and responses to music.

It seems apparent in responses by music learners that more engaged participants are consciously aware of the ways in which they use music in everyday life in comparison with less engaged participants, and use music purposefully to achieve specific goals [28]. Further research is needed to explore these engagement types and explore whether they map onto differences in real-time listening.

Moreover, present work is a rare endeavor in the area of music psychology particularly in India exploring the healing aspects of music by taking the subjective viewpoint of its lovers and practitioners. Responses of music listeners support the notion that even when people have low choice over hearing music, it generally has positive effects on them. These findings have implications for health psychology; listening to music is one way in which people can actively improve their psychological well-being and health (cf. [29]). Based on the responses on healing aspects of music, author has developed a questionnaire which is to be administered on larger group of people followed be in-depth interviews.

Lastly, findings of this study provide insight about the musical taste, the relationships between affective state and music listening, and the manifold and multilevel healing experiences with music of both music listeners and learners. These findings may be useful in designing the music intervention plans to promote psychological health and well-being in so called normal population.

\section{REFERENCES}

[1] L. Bunt, "Music therapy: An art beyond words," London: Routledge, 1994.

[2] A. C. North, D. J. Hargreaves, and J. J. Hargreaves, "Uses of music in everyday life," Music Perception, vol. 22, no. 1, pp. 47-77, 2004.

[3] A. Leblanc, "An interactive theory of music preference," Journal of Music Therapy, vol. 19, pp. 28-45, 1982.

[4] R. Müller, "Die feinen Unterschiede zwischen verbalen und klingenden Musikpräferenzen Jugendlicher, Eine computerunterstützte Befragung mit dem Fragebogen-Autorensystem-Multimedia," in K.-E. Behne, H. de la Motte-Haber \& G. Kleinen (Eds.), Jahrbuch Musikpsychologie, vol. 15, pp. 87-98, Wilhelmshaven: Noetzel, 2000.

[5] T. Schäfer, "Determinants of music preference," Unpublished doctoral thesis, 2008.

[6] J. A. Wapnick, "A review of research on attitude and preference," Bulletin of the Council for Research in Music Education, vol. 48, pp. $1-20,1976$.

[7] H. F. Abeles, "Responses to music," in D. A. Hodges (Ed.), Handbook of Music Psychology, pp. 105-140, Lawrence, KS: National Association for Music Therapy, 1980.

[8] A. LeBlanc, W. L. Sims, S. A. Malin, and C. Sherrill, "Relationships between humor perceived in music and preferences of different-age listeners," Journal of Research in Music Education, vol. 40, pp. 269282, 1992.

[9] B. L. Wheeler, "Relationship of personal characteristics to mood and enjoyment after hearing live and recorded music and to musical taste," Psychology of Music, vol. 13, no. 2, pp. 81-92, 1985.

[10] R. V. Brittin, "The effect of overtly categorizing music on preference for popular music styles," Journal of Research in Music Education, vol. 39, pp. 143-151, 1991.

[11] J. T. Humphreys, W. V. May, and D. J. Nelson, "Research on music ensembles," in R. Colwell (Ed.), Handbook of Research on Music Teaching and Learning, pp. 651-68, New York: Schirmer Books, 1992. 
[12] J. E. Palmquist, "Apparent time passage and music preference by music and nonmusic majors," Journal of Research in Music Education, vol. 38, pp. 206-214, 1990.

[13] A. LeBlanc, "Effects of style, tempo, and performing medium on children's music preference," Journal of Research in Music Education, vol. 29 , pp. 28-45, 1981

[14] J. D. Boyle, G. L. Hosterman, and D. S. Ramsey, "Factors influencing pop music preferences of young people," Journal of Research in Music Education, vol. 29, pp. 47-56, 1981.

[15] H. F. Abeles and J.W. Chung, "Responses to music," in Handbook of Music Psychology, second edition (ed. D. A. Hodges), Institute for Music Research, San Antonio, 1996.

[16] P. A. Russell, "Musical tastes and society," in The Social Psychology of Music (ed. D. J. Hargreaves and A. C. North), Oxford University Press, New York, 1997.

[17] A. Hall, "Audience personality and the selection of media and media genres," Media Psychology, vol. 7, no. 4, pp. 377-398, 2005.

[18] A. Coley, "Young people's musical taste: Relationship with gender and gender related traits," Journal of Applied Social Psychology, vol. 38, no. 8, pp. 2039-2055, 2008.

[19] S. Knobloch and D. Zillman, "Mood management via the digital jukebox," Journal of Communication, vol. 52, pp. 351-366, 2002.

[20] M. Tarrent, A. C. North, and D. J. Hargreaves, "Social categorization, self-esteem, and the estimated musical preference of male adolescents," The Journal of Social Psychology, vol. 141, no. 5, pp. 565-581, 2001.

[21] S. Frith, Performing Rites. On the Value of Popular Music, Oxford: Oxford University Press, 1996

[22] R. Rustad, J. E. Small, D. A. Jobes, M. A. Safer, and R. J. Peterson, "The impact of rock videos and music with suicidal content on thought and attitudes about suicide," Suicide and life Threatening Behavior, vol. 33, pp. 120-131, 2003.

[23] A. Wells, "Gender Emotions and popular music," Unpublished paper presented at the Midwest Sociological Society annual meeting, St Louis, Missouri, 1985.
[24] P. Laukka, "Uses of music and psychological well-being among the elderly," Journal of Happiness Studies, vol. 8, pp. 215-241, 2007.

[25] J. R. Steele and J. D. Brown, "Adolescent room culture: Studying the media in the context of everyday life," Journal of Youth and Adolescence, vol. 24, pp. 551-576, 1995.

[26] J. Anand, "Role of nonconscious processes in psychological healing," Unpublished doctoral dissertation, A.P.S. University, Rewa, India, 2005

[27] P. N. Juslin and P. Laukka, "Expression, perception, and induction of musical emotions: a review and a questionnaire study of everyday listening," Journal of New Music Research, vol. 33, pp. 217-238, 2004.

[28] A. E. Greasley and A. Lamont, "Musical preference in adulthood: Why do we like the music we do?" in M. Baroni, A.R. Addessi, R. Caterina, and M. Costa (Eds.), in Proc. the 9th International Conference on Music Perception and Cognition, pp. 960-966, Bologna: University of Bologna, 2006.

[29] K. B. Rawden and T. DeNora, "Music and informal learning in everyday life," Music Education Research, vol. 7, pp. 289-304, 2005.

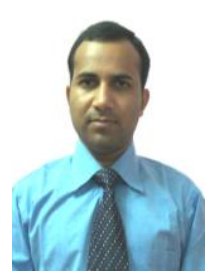

Durgesh K. Upadhyay is a lecturer in AIBAS, Amity University Uttar Pradesh, India. He has completed his D. Phil from University of Allahabad, India. His areas of interest are: Creativity in Music, Music and Education, and Music Therapy. Dr. Durgesh is also a vocalist and a regular artist in All India Radio. Dr. Durgesh is the member of IEDRC, China; SEMPRE, UK; NCMT, Chennai; and life time member of IAHP, India. Dr. Durgesh has been awarded thrice the 'SEMPRE Conference Award' by SEMPRE, UK to present his work in conferences held at Institute of Education, University of London, University of Reading, Reading and University Centre Folkestone, Folkestone. 